\title{
Ten Year Trends in Cardiovascular Risk Factors in the Federation of Bosnia and Herzegovina
}

\author{
Aida Pilav ${ }^{1,2}$, Suada Brankovic ${ }^{2}$, Vildana Doder ${ }^{1}$ \\ Federal Ministry of Health, Sarajevo, Bosnia and Herzegovina ${ }^{1}$ \\ Faculty of Health Studies, University of Sarajevo, Sarajevo, Bosnia and Herzegovina ${ }^{2}$
}

Corresponding author: Aida Pilav, MD, PhD. Sector for public health, monitoring and evaluation. Federal Ministry of Health, Titova 9. 71000 Sarajevo, Bosnia and Herzegovina. Telephone+357 33210 114. E-mail: idanap@bih.net.ba

\section{ABSTRACT}

Introduction: Results of routine health statistics show that in the Federation of Bosnia and Herzegovina (FBIH) are the leading causes of death of population are diseases of circulatory system (53\% in 2012) namely, cardiomyopathy, heart failure and acute myocardial infarction. This data are red alert for immediate and imminent action. Methods: Two cross-sectional population surveys were conducted in 2002 and 2012 in the FBIH among adult population aged 25-64 years for assessment and distribution of major risk factors for cardiovascular diseases (CVD), preferably hypertension, obesity and smoking. Results: Overall prevalence of hypertension among adult population in the FBIH in year 2012 was 41\%, similar as in 2002. Prevalence of obesity in 2012 among men was higher compared to 2002, stood at $20.3 \%$, while for women it was $24.1 \%$. Total of $61.3 \%$ of men and $35.9 \%$ of women said they were daily smokers, while the percentage in 2002 was $49.3 \%$ among men and $29.8 \%$ among women and the difference was statistically significant. Conclusions: Distributions of the major risk factors for CVD are worsening in the adult population in the FBIH, especially in middle age men, what can result in serious deterioration of health and increased rates of chronic diseases, especially CVD.
\end{abstract}

Key words: cardiovascular risk factors, Bosnia and Herzegovina, hypertension, obesity, smoking.

\section{INTRODUCTION}

Primary and secondary prevention of cardiovascular diseases (CVD) are the effective measures for reducing premature mortality. Premature mortality and morbidity from CVD are related to a common, highly preventable risk factors such as high blood pressure, obesity and smoking and their monitoring allows setting strategic directions and goals, as well as designing preventive intervention programs $(1,2,3)$. Premature mortality from CVD generally occurs in countries with low and middle national income and the Federation of Bosnia and Herzegovina (FBIH) is one of these countries (3).

FBIH is ranked among transitional countries with unstable socio-economic indicators which include high unemployment, stopped growth rate of gross domestic product (GDP), large proportion of population with low education levels, inadequacy of social protection systems and social exclusion. Recently data from FBIH showed that overall mortality rate from CVD in FBIH is over then 449/100000 inhabitants. Morbidity rate is over $10880 / 100000$ inhabitants. (4) Results of routine health statistics show that in the FBIH are the leading causes of death of population are diseases of circulatory system (53\% in 2012) namely, cardiomyopathy, heart failure and acute myocardial infarction. This data are red alert for immediate and imminent action (5).

In order to prevent early morbidity and mortality it is necessary to establish a system of supervision and monitoring of the highly preventable risk factors for CVD. In this sense, in the last ten years in the FBIH were conducted two large population studies by internationally recommended methodologies and a representative sample of the adult population.

Federal Ministry of Health (FMoH) has launched an initiative for the implementation of significant population research to monitor trends and results from population surveys. Monitoring of risk factors is essential both at strategic level through monitoring trends and distribution and at primary health care level. The great significance of this research is given population monitoring of risk factors, and after ten years it provided a comparison of two time points of measurement, and the results are needed to complete the picture and establishment of courses of action for the future period (6).

There is an imperative need for collecting population data as evidence for creating an interventional control programs of primary and secondary preventions as public health interventions based on actual evidences. In condi- 
tions of limited financial resources for health care, health systems need to devise cost-effective programs.

\section{METHODS}

Data were taken from cross-sectional population surveys on the health status population in the FBIH. Population surveys were conducted by the Federal Ministry of Health (FMoH) and the Federal Public Health Institute (FPHI) in 2002 and 2012 as a part of primary health care reform process in the $\mathrm{FBIH}$ with purpose to measure performance in the health care system and public health.

In 2002 the target population was adult population aged 25-64 years, while in the 2012 the target population was adult population aged 18 years and over. In this population were not included collective households such as student homes, children's homes, homes for elderly and pensioners. All participants were informed of the purpose of research, and were explained that the data obtained will be used exclusively for this purpose. During the survey there were also conducted anthropometric measurements (blood pressure, body weight and height), for which the written consent was sought. Comparison of major cardiovascular risk factors was conducted in both studies for adult population of 25-64 years of age.

Sample designing, conducted by the Federal institute of statistics (FIS), was based on the estimated number of people, considering that the last official census in Bosnia and Herzegovina was in the year 1991. In a study from 2002, a three-stage stratified systematic sample was applied. The total number of participants was 2750, with participation rate of $91.5 \%$.

In a survey from 2012 a framework for selection was the "master" sample were survey areas and households from 2009, which was established and updated by the FIS and that facilitated sampling compared to year 2002. It was applied the two-stage stratified systematic sample, where the primary sampling units (first stage units) were survey areas while secondary sampling units (second stage units) were households. Secondary sampling units were selected by systematic method, which ment that choice probabilities were same. Stratification of units was made according to the settlement type (urban / rural). The survey covered a total of 2735 adult population aged 25-64 years, with participation rate of $80 \%$.

Both studies were using current international methodology for this type of research. In 2012 as research instruments were used specially designed and adapted questionnaires based on international methodology (European Health Interview Survey and Health Examination Survey). For the purpose of comparison with indicators of research from 2002, set of questions was used from the recommended international protocols (WHO CINDI Health Monitor Survey, European Health Risk Monitoring Project) $(8,9)$.

Blood pressure (BP) was measured by mercury sphygmomanometer. BP was read in $\mathrm{mm} \mathrm{Hg}$ units according to the protocol MONICA research and was measured in patients homes in sitting position, after respondent had to rest for 5 minutes. Two measurements of BP were made in 2002 and three in 2012 within an interval of at least five minutes. Systolic pressure (SBP) was registered separately and diastolic blood pressure separately (DBP). Surveyed persons were classified as hypertensive if their systolic blood pressure was higher than $140 \mathrm{mmHg}$ and / or diastolic blood pressure over $90 \mathrm{mmHg}$. and / or treated with antihypertensive drugs.

Body weight was measured using digital scales and body height was measured by stadiometer at homes. Values of both body weight and body height were used to calculate the body mass index (BMI in $\mathrm{kg} / \mathrm{m} 2$ ). Limit values for overweight is $25 \mathrm{~kg} / \mathrm{m} 2$ and $30 \mathrm{~kg} / \mathrm{m} 2$ for obesity.

Smoking status was assessed using a set of questions, according to the European Health Risk Monitoring Project protocol. Subjects were divided into three categories-daily smokers, former smokers and those who never smoked. Based on this, comparison of the results was performed in two separate studies inside a decade.

For values of the main indicators in both studies for the research there were performed same statistical analyzes. Analysis of variance was used to compare average values of continuous variables (BMI) by sex and age. Differences in obesity, prevalence of hypertension and smoking status, as well as the interaction among age and sex groups was tested by a log-linear model.

\section{RESULTS}

\subsection{Blood pressure}

Overall prevalence of hypertension in the adult population in the FBIH in year 2012 was $41 \%$, it was higher in men (43.9\%) rather than women $(37.5 \%)$ and generally there were no significant differences compared to the overall prevalence of research in the year 2002. There was a statistically significant prevalence of hypertension in both men and women and it significantly increased with the age $(\mathrm{p}<0.01)$. Prevalence of hypertension in men in the previous study of 2002 stood at $41 \%$ and was more common in women.

In the men group, in 2012, there was an increase of $8 \%$ of hypertension cases compared to 2002 (up from 36\% in the 2002 to $44 \%$ in 2012). In women, the reverse trend is observed in the 2012 , a decline of $8 \%$ of hypertension cases compared to 2002 . (45\% vs. $38 \%$ ) (Table 1.)

\subsection{Body Mass Index}

In a study from 2002 there was no statistically significant difference in average body mass index (BMI), which in men was $26.5 \mathrm{~kg} / \mathrm{m} 2$ and $27.0 \mathrm{~kg} / \mathrm{m} 2$ in women. BMI has consecutively increased with age in both sexes, and significantly in women ( $\mathrm{p}<0.01$ ). BMI values in the 2012 are lower, and also, there was no statistically significant difference between men and women $(26.9 \mathrm{~kg} / \mathrm{m} 2$ vs. 26.4 $\mathrm{kg} / \mathrm{m} 2)$. BMI increases with age in both sexes ( $\mathrm{p}<0.01)$. The interaction is presented in Graph 1.

In men, there is a statistically significant increase in BMI in the 2012 compared to 2002. $(\mathrm{p}<0.01)$. Analysis based of the simple main effect of age for men shows that in the group of men, by increasing age there is a proper, statistically significant increase in body mass index in both years of measurement $(\mathrm{p}<0.01)$. According to measurement year, in a group of women it is coming to the statistically significant decline in BMI in the 2012 compared to 2002. $(\mathrm{p}<0.01)$ Increase in age leads to proper, statistically significant increase in body mass index. $(\mathrm{p}<0.01)$ (Table 2$)$ 


\begin{tabular}{|c|c|c|c|c|c|c|}
\hline \multirow{3}{*}{ Year } & \multirow{3}{*}{ Sex } & \multirow{3}{*}{ Age } & \multicolumn{4}{|c|}{ Hypertension } \\
\hline & & & \multicolumn{2}{|c|}{ Normotensive } & \multicolumn{2}{|c|}{ Hypertensive } \\
\hline & & & $\mathrm{N}$ & $\%$ & $\mathrm{~N}$ & $\%$ \\
\hline \multirow{11}{*}{2002.} & \multirow{5}{*}{$\sum_{\Sigma}^{\tilde{E}}$} & $25-34$ & 145 & $87.9 \%$ & 20 & $12.1 \%$ \\
\hline & & $35-44$ & 254 & $74.7 \%$ & 86 & $25.3 \%$ \\
\hline & & $45-54$ & 190 & $59.6 \%$ & 129 & $40.4 \%$ \\
\hline & & $55-64$ & 120 & $43.2 \%$ & 158 & $56.8 \%$ \\
\hline & & Total & 709 & $64.3 \%$ & 393 & $35.7 \%$ \\
\hline & \multirow{5}{*}{ 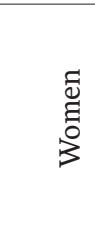 } & $25-34$ & 277 & $87.9 \%$ & 38 & $12.1 \%$ \\
\hline & & $35-44$ & 318 & $71.5 \%$ & 127 & $28.5 \%$ \\
\hline & & $45-54$ & 182 & $43.5 \%$ & 236 & $56.5 \%$ \\
\hline & & $55-64$ & 100 & $23.6 \%$ & 324 & $76.4 \%$ \\
\hline & & Total & 877 & $54.7 \%$ & 725 & $45.3 \%$ \\
\hline & Total & & 1586 & $58.7 \%$ & 1118 & $41.3 \%$ \\
\hline \multirow{11}{*}{2012} & \multirow{5}{*}{$\sum^{\mathbb{e}}$} & $25-34$ & 253 & $83.2 \%$ & 51 & $16.8 \%$ \\
\hline & & $35-44$ & 202 & $65.8 \%$ & 105 & $34.2 \%$ \\
\hline & & $45-54$ & 175 & $51.2 \%$ & 167 & $48.8 \%$ \\
\hline & & $55-64$ & 79 & $25.5 \%$ & 231 & $74.5 \%$ \\
\hline & & Total & 709 & $56.1 \%$ & 554 & $43.9 \%$ \\
\hline & \multirow{5}{*}{ 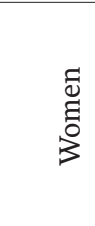 } & $25-34$ & 288 & $89.2 \%$ & 35 & $10.8 \%$ \\
\hline & & $35-44$ & 269 & $80.5 \%$ & 65 & $19.5 \%$ \\
\hline & & $45-54$ & 228 & $54.7 \%$ & 189 & $45.3 \%$ \\
\hline & & $55-64$ & 106 & $30.1 \%$ & 246 & $69.9 \%$ \\
\hline & & Total & 891 & $62.5 \%$ & 535 & $37.5 \%$ \\
\hline & Total & & 1600 & $69.5 \%$ & 1089 & $40.5 \%$ \\
\hline Total & & & 3186 & $59.1 \%$ & 2207 & $40.9 \%$ \\
\hline
\end{tabular}

Table 1. Prevalence of hypertension, by sex and age, 2002. and 2012.

Hierarchical log-linear analysis with backward elimination effects

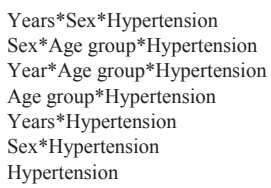

$\begin{array}{ll}\mathrm{df}=1 & \text { Partial } \chi^{2}=50.4 \\ \mathrm{df}=3 & \text { Partial } \chi^{2}=19.5 \\ \mathrm{df}=3 & \text { Partial } \chi^{2}=3.8 \\ \mathrm{df}=3 & \text { Partial } \chi^{2}=1051.1 \\ \mathrm{df}=1 & \text { Partial } \chi^{2}=0.1 \\ \mathrm{df}=1 & \text { Partial } \chi^{2}=1.5 \\ \mathrm{df}=1 & \text { Partial } \chi^{2}=178.7\end{array}$

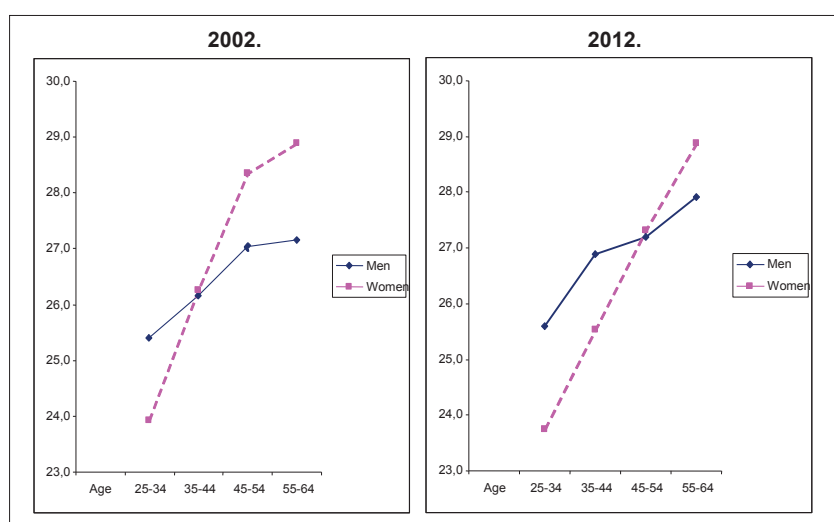

Graph 1, Body mass index, by year and sex

Prevalence of obesity (BMI> $30 \mathrm{~kg} / \mathrm{m} 2)$ in 2002 was $16.5 \%$ among men and $21.7 \%$ among women and it significantly increased with age in both sexes. In 2012, prevalence of obesity in men was higher compared to 2002, stood at $20.3 \%$, while for women it was $24.1 \%$. Increase in prevalence of obesity increases significantly with age, with an increase steeper in women. In women, prevalence of obesity in 2012 decreased in the age group 35-54 com-

\begin{tabular}{|c|c|c|c|c|c|c|c|}
\hline & & \multicolumn{6}{|c|}{ Year } \\
\hline & & & 2002. & & & 2012. & \\
\hline \multicolumn{2}{|l|}{ Sex } & $\mathrm{N}$ & $\mathrm{M}$ & SD & $\mathrm{N}$ & $\mathrm{M}$ & SD \\
\hline \multirow{5}{*}{$\sum_{\Sigma}^{e}$} & $25-34$ & 173 & 25.40 & 3.74 & 301 & 25.60 & 3.11 \\
\hline & $35-44$ & 347 & 26.15 & 3.41 & 302 & 26.88 & 3.58 \\
\hline & $45-54$ & 321 & 27.03 & 3.44 & 338 & 27.19 & 3.73 \\
\hline & $55-64$ & 277 & 27.14 & 3.79 & 303 & 27.90 & 3.68 \\
\hline & Total & 1118 & 26.53 & 3.62 & 1244 & 26.90 & 3.63 \\
\hline \multirow{5}{*}{ 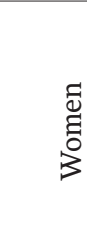 } & $25-34$ & 322 & 23.92 & 4.06 & 305 & 23.74 & 4.04 \\
\hline & $35-44$ & 449 & 26.25 & 4.47 & 333 & 25.53 & 4.35 \\
\hline & $45-54$ & 420 & 28.35 & 4.94 & 414 & 27.31 & 5.15 \\
\hline & $55-64$ & 422 & 28.88 & 4.72 & 345 & 28.87 & 5.33 \\
\hline & Total & 1613 & 27.02 & 4.94 & 1397 & 26.49 & 5.14 \\
\hline
\end{tabular}

Table 2. Body Mass Index, by sex and age, 2002. and 2012.

$\begin{array}{llllll}\text { *Analysis of Variance (ANOVA) } & & & & \\ \text { Sex } & \mathrm{SS}=3.7 & \mathrm{df}=1 & \mathrm{MS}=3.7 & \mathrm{~F}=0.2 & \mathrm{p}>0.001 \\ \text { Age group } & \mathrm{SS}=8439.9 & \mathrm{df}=3 & \mathrm{MS}=2813.3 & \mathrm{~F}=157.7 & \mathrm{p}<0.001 \\ \text { Year } & \mathrm{SS}=0.2 & \mathrm{df}=1 & \mathrm{MS}=0.2 & \mathrm{~F}=0.0 & \mathrm{p}>0.001 \\ \text { Sex*Age group } & \mathrm{SS}=1643.9 & \mathrm{df}=3 & \mathrm{MS}=548.0 & \mathrm{~F}=30.7 & \mathrm{p}<0.001 \\ \text { Sex*Year } & \mathrm{SS}=289.7 & \mathrm{df}=1 & \mathrm{MS}=289.7 & \mathrm{~F}=16.2 & \mathrm{p}<0.001 \\ \text { Age group*Year, } & \mathrm{SS}=115.6 & \mathrm{df}=3 & \mathrm{MS}=38.5 & \mathrm{~F}=2.2 & \mathrm{p}>0.001 \\ \text { Sex*Age group*Year } & \mathrm{SS}=50.5 & \mathrm{df}=3 & \mathrm{MS}=16.8 & \mathrm{~F}=0.9 & \mathrm{p}>0.001\end{array}$

pared to the results of 2002, while in similar age group in men that percentage increased.

In the men group, during both years of measurement, the largest percentage of respondents, nearly $50 \%$ was in the category of BMI $25-29 \mathrm{~kg} / \mathrm{m} 2$ followed by categories $<25 \mathrm{~kg} / \mathrm{m} 2$ (35\% 2002 and 30\% in 2012) and categories of $>30 \mathrm{~kg} / \mathrm{m} 2$ (17\% and 20\% respectively in 2012). Among women, the frequency of subjects in the categories of BMI in both years, proper declining from category of $<25 \mathrm{~kg} /$ $\mathrm{m} 2$ to category $<30 \mathrm{~kg} / \mathrm{m} 2$.

\subsection{Smoking}

In the $\mathrm{FBiH}$ in $2012,61.3 \%$ of men and $35.9 \%$ of women said they were daily smokers, while the percentage in 2002 was 49.3\% among men and 29.8\% among women and the difference was statistically significant $(\mathrm{p}<0.01)$. Prevalence of daily smokers in 2012 increased with age, especially in men, while in 2002 the prevalence of smoking decreased with age in both men and women. Within the two youngest age groups (25-44), the percentage of daily smokers in both sexes has remained almost the same in both years of measurement. On the other hand, in the age group 45-64, the percentage of daily smokers significantly increased from 2002 to 2012 in both sexes, particularly in men. The prevalence of people who have never smoked in the study from 2012 was lower than in 2002 study and there were more women. In the younger groups, the percentage of smokers in 2012 had increased (approximately 3\% in men aged 25-34 and almost 13\% in women aged 25-34).

In older age groups the percentage dropped in 2012 compared to 2002 , about $7 \%$ in men aged $45-54$ and almost $10 \%$ in men aged 55-64, and 13\% among women aged $45-54$ and about 9\% in women aged 55-64. Prevalence of former smokers in both men and women stood at 


\begin{tabular}{|c|c|c|c|c|c|c|c|c|}
\hline \multirow{3}{*}{ Year } & \multirow{3}{*}{ Sex } & \multirow{3}{*}{ Age } & \multicolumn{6}{|c|}{ Body Mass Index $\left(\mathrm{kg} / \mathrm{m}^{2}\right)$} \\
\hline & & & \multicolumn{2}{|c|}{$<25 \mathrm{~kg} / \mathrm{m}^{2}$} & \multicolumn{2}{|c|}{$\begin{array}{c}25 \mathrm{~kg} / \mathrm{m}^{2}-29 \\
\mathrm{~kg} / \mathrm{m}^{2}\end{array}$} & \multicolumn{2}{|c|}{$>30 \mathrm{~kg} / \mathrm{m}^{2}$} \\
\hline & & & $\mathrm{N}$ & $\%$ & $\mathrm{~N}$ & $\%$ & $\mathrm{~N}$ & $\%$ \\
\hline \multirow{11}{*}{ ઠิ } & \multirow{5}{*}{$\sum_{\Sigma}^{ \pm}$} & -34 & 86 & $49.7 \%$ & 67 & $38.7 \%$ & 20 & $11.6 \%$ \\
\hline & & $35-44$ & 130 & $37.5 \%$ & 170 & $49.0 \%$ & 47 & $13.5 \%$ \\
\hline & & $45-54$ & 93 & $29.0 \%$ & 169 & $52.6 \%$ & 59 & $18.4 \%$ \\
\hline & & $55-64$ & 81 & $29.2 \%$ & 137 & $49.5 \%$ & 59 & $21.3 \%$ \\
\hline & & Total & 390 & $34.9 \%$ & 543 & $48.6 \%$ & 185 & $16.5 \%$ \\
\hline & \multirow{5}{*}{ 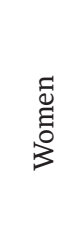 } & $25-34$ & 222 & $68.9 \%$ & 79 & $24.5 \%$ & 21 & $6.5 \%$ \\
\hline & & $35-44$ & 202 & $45.0 \%$ & 167 & $37.2 \%$ & 80 & $17.8 \%$ \\
\hline & & $45-54$ & 112 & $26.7 \%$ & 169 & $40.2 \%$ & 139 & $33.1 \%$ \\
\hline & & $55-64$ & 87 & $20.6 \%$ & 168 & $39.8 \%$ & 167 & $39.6 \%$ \\
\hline & & Total & 623 & $38.6 \%$ & 583 & $36.1 \%$ & 407 & $25.2 \%$ \\
\hline & Total & & 1013 & $37.1 \%$ & 1126 & $41.2 \%$ & 592 & $21.7 \%$ \\
\hline \multirow{11}{*}{ ठำ } & \multirow{5}{*}{ 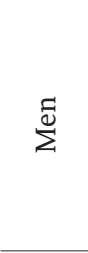 } & -34 & 128 & $42.5 \%$ & 149 & $49.5 \%$ & 24 & $8.0 \%$ \\
\hline & & $35-44$ & 92 & $30.5 \%$ & 153 & $50.7 \%$ & 57 & $18.9 \%$ \\
\hline & & $45-54$ & 91 & $26.9 \%$ & 168 & $49.7 \%$ & 79 & 23.4 \\
\hline & & $55-64$ & 59 & $19.5 \%$ & 151 & $49.8 \%$ & 93 & 30.7 \\
\hline & & Total & 370 & $29.7 \%$ & 621 & $49.9 \%$ & 253 & $20.3 \%$ \\
\hline & \multirow{5}{*}{ 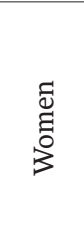 } & $25-34$ & 218 & $71.5 \%$ & 64 & $21.0 \%$ & 23 & $7.5 \%$ \\
\hline & & $35-44$ & 172 & $51.7 \%$ & 113 & $33.9 \%$ & 48 & $14.4 \%$ \\
\hline & & $45-54$ & 144 & $34.8 \%$ & 144 & $34.8 \%$ & 126 & $30.4 \%$ \\
\hline & & $55-64$ & 01 & $23.5 \%$ & 125 & $36.2 \%$ & 139 & $40.3 \%$ \\
\hline & & Total & 615 & $44.0 \%$ & 446 & $31.9 \%$ & 336 & $24.1 \%$ \\
\hline & Total & & 985 & $37.3 \%$ & 1067 & $40.4 \%$ & 589 & $22.3 \%$ \\
\hline $\mathrm{T}$ & & & 1998 & $37.2 \%$ & 2193 & $40.8 \%$ & 1181 & $22.0 \%$ \\
\hline
\end{tabular}

Table 3. Prevalence of obesity, by sex and age, 2002. and 2012.

$\begin{array}{llll}\text { Hierarchical log-linear analysis with backward elimination effects } & \\ \text { Year*Sex*BMI } & \mathrm{df}=2 & \text { Partial } \chi^{2}=22.7 & \mathrm{p}<.001 \\ \text { Sex*Age*BMI } & \mathrm{df}=6 & \text { Partial } \chi^{2}=40.8 & \mathrm{p}<.001 \\ \text { Year*Age*BMI } & \mathrm{df}=6 & \text { Partial } \chi^{2}=5.707 & \mathrm{p}>.05 \\ \text { Sex*BMI } & \mathrm{df}=2 & \text { Partial } \chi^{2}=125.7 & \mathrm{p}<.001 \\ \text { Age*BMI } & \mathrm{df}=6 & \text { Partial } \chi^{2}=512.5 & \mathrm{p}<.001 \\ \text { Year*BMI } & \mathrm{df}=2 & \text { Partial } \chi^{2}=1.944 & \mathrm{p}>.05 \\ \text { BMI } & \mathrm{df}=2 & \text { Partial } \chi^{2}=343.6 & \mathrm{p}<.001\end{array}$

$5.4 \%$ in 2012 and was significantly lower than in the study from 2002 when it stood at $8.3 \%$. (Table 4.)

\section{DISCUSSION}

CVD are the prominent causes of death and disability in the world, and estimates for the prevalence of risk factors for their formation and development is necessary for creating promotional and prevention programs, especially in the work of primary health care. Leading risk factors for CVD are behavioral, in the first place increased body weight, obesity and smoking, and also increased uncontrolled blood pressure which makes a significant pathophysiological risk factor $(2,3)$.

In the FBIH, a total of $41 \%$ of the respondents were registered as hypertensive and there was no significant change in prevalence in relation to the 2002 study. $(9,10)$ Prevalence of hypertension in the $\mathrm{FBiH}$ in comparison with the countries of this part of Europe is similar, particularly in comparison with Croatia and Slovenia, while

\begin{tabular}{|c|c|c|c|c|c|c|c|c|}
\hline \multirow{3}{*}{ Year } & \multirow{3}{*}{ Sex } & \multirow{3}{*}{ Age } & \multicolumn{6}{|c|}{ Smoking status } \\
\hline & & & \multicolumn{2}{|c|}{ Daily smokers } & \multicolumn{2}{|c|}{$\begin{array}{l}\text { Former } \\
\text { smokers }\end{array}$} & \multicolumn{2}{|c|}{ Non-smokers } \\
\hline & & & $\mathrm{N}$ & $\%$ & $\mathrm{~N}$ & $\%$ & $\mathrm{~N}$ & $\%$ \\
\hline \multirow{11}{*}{$\begin{array}{l}\text { ঠें } \\
\text { ঠे }\end{array}$} & \multirow{5}{*}{$\sum_{\Sigma}^{\mathbb{d}}$} & $25-34$ & 92 & $53.2 \%$ & 9 & $5.2 \%$ & 72 & $41.6 \%$ \\
\hline & & $35-44$ & 192 & $55.3 \%$ & 24 & $6.9 \%$ & 131 & $37.8 \%$ \\
\hline & & $45-54$ & 157 & $48.9 \%$ & 31 & $9.7 \%$ & 133 & $41.4 \%$ \\
\hline & & $55-64$ & 111 & $39.8 \%$ & 56 & $20.1 \%$ & 112 & $40.1 \%$ \\
\hline & & Total & 552 & $49.3 \%$ & 120 & $10.7 \%$ & 448 & $40.0 \%$ \\
\hline & \multirow{5}{*}{$\begin{array}{l}\text { छี } \\
\text { छี } \\
\text { క }\end{array}$} & $25-34$ & 123 & $37.6 \%$ & 30 & $9.2 \%$ & 174 & $53.2 \%$ \\
\hline & & $35-44$ & 163 & $36.1 \%$ & 33 & $7.3 \%$ & 255 & $56.5 \%$ \\
\hline & & $45-54$ & 122 & $29.2 \%$ & 22 & $5.3 \%$ & 274 & $65.6 \%$ \\
\hline & & $55-64$ & 75 & $17.6 \%$ & 22 & $5.2 \%$ & 329 & $77.2 \%$ \\
\hline & & Total & 483 & $29.8 \%$ & 107 & $6.6 \%$ & 1032 & $63.6 \%$ \\
\hline & Total & & 1035 & $37.7 \%$ & 227 & $8.3 \%$ & 1480 & $54.0 \%$ \\
\hline \multirow{11}{*}{$\stackrel{\stackrel{ }{\circ}}{\text { ㄱ }}$} & \multirow{5}{*}{$\sum^{\mathbb{D}}$} & $25-34$ & 155 & $51.0 \%$ & 12 & $3.9 \%$ & 137 & $45.1 \%$ \\
\hline & & $35-44$ & 193 & $62.9 \%$ & 5 & $1.6 \%$ & 109 & $35.5 \%$ \\
\hline & & $45-54$ & 218 & $63.7 \%$ & 9 & $2.6 \%$ & 115 & $33.6 \%$ \\
\hline & & $55-64$ & 208 & $67.1 \%$ & 8 & $2.6 \%$ & 94 & $30.3 \%$ \\
\hline & & Total & 774 & $61.3 \%$ & 34 & $2.7 \%$ & 455 & $36.0 \%$ \\
\hline & \multirow{5}{*}{$\begin{array}{l}\text { Eี } \\
\text { है } \\
3\end{array}$} & $25-34$ & 101 & $31.3 \%$ & 7 & $2.2 \%$ & 215 & $66.6 \%$ \\
\hline & & $35-44$ & 117 & $35.0 \%$ & 5 & $1.5 \%$ & 212 & $63.5 \%$ \\
\hline & & $45-54$ & 189 & $45.3 \%$ & 11 & $2.6 \%$ & 217 & $52.0 \%$ \\
\hline & & $55-64$ & 105 & $29.8 \%$ & 7 & $2.0 \%$ & 240 & $68.2 \%$ \\
\hline & & Total & 512 & $35.9 \%$ & 30 & $2.1 \%$ & 884 & $62.0 \%$ \\
\hline & Total & & 1286 & $47.8 \%$ & 64 & $2.4 \%$ & 1339 & $49.8 \%$ \\
\hline Total & & & 2321 & $42.7 \%$ & 291 & $5.4 \%$ & 2819 & $51.9 \%$ \\
\hline
\end{tabular}

Table 4. Smoking prevalence, by sex and age, 2002. and 2012.

Hierarchical log-linear analysis with backward elimination effects Year*Age*Smoking $\quad \mathrm{df}=6 \quad$ Partial $\chi^{2}=52.7$ Sex*Age*Smoking $\quad \mathrm{df}=6 \quad$ Partial $\chi^{2}=42.1$ $\begin{array}{lll}\text { Year*Sex*Smoking } & \mathrm{df}=2 & \text { Partial } \chi^{2}=1.285\end{array}$ Year*Smoking $\quad \mathrm{df}=2 \quad$ Partial $\chi^{2}=126.1$ Sex*Smoking $\quad \mathrm{df}=2 \quad$ Partial $\chi^{2}=330.4$ Age*Smoking $\quad \mathrm{df}=6 \quad$ Partial $\chi^{2}=38.5$

it is lower than the results of recently conducted research in Serbia (11-14).

Compared with average prevalence of hypertension in the world in recent estimates, the FBIH is significantly above average. Prevalence of hypertension varies widely in all the countries of the world, but implementation of interventions, well-controlled programs all reduce the prevalence of hypertension as significant risk factor for cardiovascular disease $(15,16)$. Since there is observed increase in prevalence, especially in men, in the FBIH it is necessary to take urgent public health intervention programs aimed at increasing awareness of the population about hypertension, timely detection, treatment and control of high blood pressure, in order that burden of this serious health problem would not increase in the future.

The overall prevalence of obesity was $22 \%$ and it was higher among women. In relation to the value of 2002, there has been a slight increase in obesity, especially among men. These are the predictions of the previous research on populations, but values are still lower than in the EU, where it is estimated that over $60 \%$ of the adult population is overweight or obese (17). 
Overweight and obesity are major risk factors for many chronic diseases, particularly CVD and diabetes mellitus. Transitional countries in southeastern Europe are increasingly faced with the rise of obesity and it is evident in recent research in population. Worrying trends in obesity should initiate intense activities to promote proper nutrition and regular physical activity for all age groups, including younger people, because it is found an increase in overweight and obesity, especially among younger men (19). Good possibility would be a strengthened primary health care in the $\mathrm{FBiH}$ and a well-established network of family medicine teams. Public health institutes in the $\mathrm{FBiH}$ should take the leading role for these ideas and create interventional programs.

Smoking is a well-known behavioral risk factor in the development of many chronic diseases and the fight against smoking is a long-term activity in all the countries of the world. The prevalence of smoking shows a steady upward trend in the countries of both central and southeastern Europe, as demonstrated by this study in the FBIH. The overall prevalence of smoking in FBIH was 49\%, significantly higher in men, even $62 \%$, and showed an increasing trend among the adult population in the last ten years. For males, the prevalence of smoking has dramatically increased in all age groups, while the prevalence of smoking among women was significant in older age groups. Compared to neighboring countries, the $\mathrm{FBiH}$ was leading this area. Recent cross-sectional research in both Serbia and Croatia showed significantly lower values, as well as the declining trends in previous years $(19,20)$.

High prevalence of smoking in the future will have significant implications on the rate of premature morbidity from chronic diseases, on death and disability. Necessary is further continuous research of social and situational variables in developing smoking habits, and also taking a stronger process for smoking cessation and making of positive environmental conditions that will lead to continuous long-term reduction in smoking habits in the population (prohibition of advertising, areas exempted from the cigarette smoke, etc.) Distributions of the major risk factors for CVD are worsening in the adult population in the FBIH, especially in middle age men, what can result in serious deterioration of health and increased rates of chronic diseases, especially CVD.

\section{CONCLUSIONS}

Trends in major risk factors in the FBIH show a strong need for progressive modifications of lifestyles by setting strong and controlled interventional preventive and promotional programs. As countries with transitional economies in Southeast Europe have similar trends, it opens up the possibility for collaborative studies and interventional programs, exchange of ideas and best practice, what should all be strongly supported.

\section{Acknowledgments}

The survey was made as a part of the Health sector enhancement project in the Federation of Bosnia and Herzegovina, implemented through Federal Ministry of Health in collaboration with Federal Public Health Institute, funded by the World Bank from the International Development Association (IDA) credit and authors would like to acknowledge.

\section{CONFLICT OF INTEREST: NONE DECLARED.}

\section{REFERENCES}

1. Global status report on non communicable diseases 2010. World Health Organization, 2011.

2. Health 2020. A European policy framework and strategy for the 21st century. World Health Organization, 2013.

3. Action plan for implementation of the European Strategy for the Prevention and Control of Non communicable Diseases 20122016. World Health Organization Regional Office for Europe, 2011.

4. Masic I, Dilic M, Raljevic E, Vulic D, Mott D. Trends in Cardiovascular Diseases in Bosnia and Herzegovina and Perspectives with HeartScore Programme. Med Arh. 2010; 64(5): 260-263.

5. Health status and organization of health care in the Federation of Bosnia and Herzegovina, 2012. Federal Public Health Institue of FBIH, Sarajevo 2003.

6. Strategic plan of health system in the FBIH 2008-2018. Federal Ministry of Health. 2008.

7. The European Health Interview Survey, EHIS. EUROSTAT 2010.

8. WHO MONICA Project. Survey protocol. http://www.thl.fi/publications/monica/manual/index.htm

9. Istraživanje riziko faktora nezaraznih bolesti u Federaciji Bosne i Hercegovine 2002. Zavod za javno zdravstvo FBIH, 2003.

10. Pilav A, Nissinen A, Haukkala A, Nikšić D, Laatikainen T. Cardiovascular risk factors in the Federation of Bosnia and Herzegovina. European Journal of Public Health. 2007; 17(1): 75-79.

11. Bulc M. Fras Z, Zaletel-Kragelj L. Twelve-year Blood Pressure Dynamics in Adults in Ljubljana Area, Slovenia: Contribution of WHO Countrywide Integrated Non communicable Diseases Intervention Program. Croat Med J. 2006; 47: 469-477.

12. Brborović $\mathrm{O}$, Vukušić-Rukavina T, Fazlić H, Vuletić S, Kern J, Pavleković G. Case oriented approach to co-occurrence of risk lifestyle behaviour with overweight, excess abdominal fat and high blood pressure: The CroHort Study. Coll. Antropol. 2012; 36(1): 15-19.

13. Petrela E, Burazeri G, Pupuleku F, Zaimi E, Rahman M. Prevalence and correlates of hypertension in a transitional Southeastern European population: Results from the Albanian Demographic and Health Survey. Arh Hig Rada Toksikol. 2013; 64: 479-487.

14. Grujić V, Dragnić N, Kvrgić S, Šušnjević S, Grujić J, Travar S. Epidemiology of Hypertension in Serbia: Results of a National Survey. J Epidemiol. 2012; 22(3): 261-266.

15. McAlister F.A, Wilkins K, Joffres M, Leenen F.H.H, Fodor G, Gee $M$. et all. Changes in the rates of awareness, treatment and control of hypertension in Canada over the past two decades. CMAJ. 2011; 183(9): 1007-1013.

16. Danaei G, Finucane MM, Lin JK, et al. National, regional, and global trends in systolic blood pressure since 1980: systematic analysis of health examination surveys and epidemiological studies with 786 country-years and 5.4 million participants. Lancet. 2011; 377: 568-577.

17. Diet, nutrition and the prevention of chronic diseases. Report of a joint WHO/FAO expert consultation, 28 January-1 February 2002, Geneva, Switzerland (WHO Technical Report Series 916).

18. Nissinen A, Ximena B, Puska P. Community-based non communicable disease interventions: lessons from developed countries for developing ones. Bulletin of the World Health Organization. 2001; 79: 963-970

19. Djikanovic B, Marinkovic J, Jankovic J, Vujanac V, Simic S. Gender differences in smoking experience and cessation: do wealth and education matter equally for women and men in Serbia? Journal of Public Health. 2000; 33(1): 31-38.

20. Samardžić S, Vuletić G, Tadijan D. Five-year cumultaive incidence of smoking in adult croatian population: the CroHort Study. Coll Antropol. 2012; 36(1): 99-103.

21. Integrated management of cardiovascular risk: report of a WHO meeting Geneva, 9-12 July 2002. WHO, 2002. 